\title{
A COMPUTER MODEL DESIGNED TO EVALUATE THE FIREFIGHTING EFFECTIVENESS OF SOLID JET PRODUCED BY WATER NOZZLE
}

\author{
Jerzy GAŁAJ ${ }^{1 *}$, Tomasz DRZYMAŁA ${ }^{1}$, Ritoldas ŠUKYS², Piotr TOFIŁO ${ }^{1}$ \\ ${ }^{1}$ Faculty of Fire Safety Engineering, The Main School of Fire Service, Slowackiego St. 52/54, \\ 01-692 Warsaw, Poland \\ ${ }^{2}$ Department of Labour Safety and Fire Protection, Faculty of Civil Engineering, \\ Vilnius Gediminas Technical University, Sauletekio al. 11, LT-10223 Vilnius, Lithuania
}

Received 16 September 2017; accepted 07 November 2017

\begin{abstract}
The paper begins with a brief introduction and review of international research in the area of water jet streams and their effectiveness in firefighting. Then a general concept of a new numerical model for firefighting process using solid jet produced by water nozzle is presented. The provided description of the model includes main assumptions for extinguishing process and a set of relationships representing a mathematical model. The paper also includes block diagrams of the main program algorithms and procedures designed to determine the value of the surface and sprinkling intensity depending on the input data like nozzle dimensions, position etc. Input parameters which are necessary for the calculation are discussed, together with a general concept of the users input and output interfaces and simulation tests that can be performed using the developed model. Some selected simulation tests in tabular and graphical forms are included. Summary and general conclusions can be found at the end.
\end{abstract}

Keywords: extinguishing effectiveness, solid jet, water nozzle, computer extinguishing model, extinguishing process, computer model.

\section{Introduction}

Firefighting can be defined as a series of complex actions depending on development of the situation. You could say that extinction always varies, because there are no two identical events, two fires that would develop in the same way. However, in order to prepare effective firefighting operations some similarities are used, repeatable phenomenon, which lead to the development of certain types of action (Särdqvist 2016).

In firefighting the following types of action can be distinguished:
a) attack;
b) defense;
c) combined actions.

The attack is a main form of tactical action and involves direct impact on source of fire to stop the combustion process. The effectiveness of the attack, and thus the rate of interrupting this process, depends inter alia on the ability of introducing the extinguishing agent into the combustion zone or the use of fire-fighting equipment with the proper parameters (output, pressure, range, etc.).
Defense, in turn, is an indirect form of action that directs extinguishing streams into objects at risk of fire. It is very rare, in practice, to use only one of the above mentioned forms - most commonly combined actions are used. The aim is to reduce the rate of spread of fire while protecting objects in its vicinity. This requires a very good organization of the firefighting positions, which should manifest itself in close cooperation between rescuers and conducting continuous reconnaissance of the situation. Water ranks high in all sorts of extinguishing agents classifications. This state of affairs can be attributed to its widespread availability, low price, ease of transport and delivery to the fire, the possibility of pumping over long distances, as well as centuries-old tradition of its application. Due to the high specific heat $(4189.9 \mathrm{~J} /(\mathrm{kgK}))$ and the heat of vaporization $(2257 \mathrm{~kJ} / \mathrm{kg})$, basis of the extinguishing action with water is cooling effect, which consists in removing from a fire (with flame and burning surface) of a quantity of heat, the temperature of the burning material is reduced below its flash point. The cooling effect is caused by the evapora-

*Corresponding author. E-mail: jerzy.galaj@gmail.com 
tion of water. A minor role in this case plays the damping effect, which completely or partially prevents air supply to a fire. A final result of the actions of firefighting water is therefore a sum effect of cooling and damping (Grimwood 2002; Svensson, Särdqvist 2002; Särdqvist 2016; Zbrożek, Prasuła 2009).

The water in firefighting is used in a form of solid and spray jets. The latter are divided into spray and mist streams. Solid jets are characterized by long range and small size of sprinkling area. Another advantage is high kinetic energy of the solid water stream, which causes easy infiltration of water into the combustion zone. A drawback is insignificant use of cooling action (about 10\%) and ability to break down structural elements of the building. For these reasons, use of solid jets mainly refers to the following situations:

a) extinguishing a solid body with fire heavily developed;

b) need to provide water from a long distance;

c) use mechanical energy of the stream to capture.

Research in the area of water streams and their effectiveness was conducted by many international researchers. Some important reviews were published by Grant et al. (2000) as thorough report from research program led by UK Home Office Fire Research and Development Group. Fires characteristics, sprays, modes of application of firefighting water, droplet characteristics and some experimental data were included in the report. Novozhilov (2007) proposed a criterion for the optimum spray dynamics and provided an analytical estimation for optimum droplet size in the spray as a function of Heat Release Rate of fire. His mathematical model is based on approximate solution of the Lagrangian equation for the motion of water droplets. More recent studies on water jets and sprays were conducted at NIST and the University of Maryland lead by prof. Marshall. Zheng and Ryder (2010) have reported an initial work related to a new model development which involves a very detailed characterization of the water stream in terms of breakup patterns and droplet distributions. Salyers (2010) has provided a very thorough and up-to-date review of spray characteristics from modern fire hose nozzles. Willi et al. (2016) have studied experimentally the impact of hose streams on air flows in a building during firefighting. Some important results for this research area can be adopted from the sprinkler spray research and general CFD modeling of sprays and jets (Wu et al. 2007; Marshall, di Marzo 2004; Ren et al. 2011; Myers, Marshall 2016). Droplet distributions were also studied elsewhere (Yoon 2005; Babinsky, Sojka 2002). Flame extinction was recently studied by White et al. (2017).

Definitely better, especially with extinction of rooms, is to use the spray jets. Their greater extinguishing efficiency is associated with a greater surface area of water, which enhances effect of suppression. More water in a form of droplets reaches the combustion zone and is evaporated, thereby receiving larger amount of heat from a fire. The use of spray jets is considered to be a basic method of operation during firefighting, where important is not only the fact of fire suppression, but also to do so using the least amount of water. This includes minimize the amount of water provided to limit the damage caused by its action, good organization of firefighting stations or selection of type of jet (Grimwood 2002; Svensson, Särdqvist 2002). Stopping a reaction of combustion is possible when the flow of extinguishing agent absorbs the heat faster (more) than it is produced by the burning material. The sooner this happens; the water consumption will be reduced. Some studies on computer extinguishing models and experiments with distribution of droplets diameters in the spray can be found in Gałaj and Drzymała (2015), Gałaj and Saramański (2014), Gałaj and Koszykowski (2014). After some modifications, especially regarding model of combustion zone, proposed model of extinguishing process can be applied in zone, field or hybrid fire model.

This work involves issues that are rarely discussed in world literature. Based on the available sources, it can be concluded that they lack the description of a digital model of the extinguishing process of the fire with the solid or spray jets produced by water nozzles. This work seeks to fill this gap, especially since the demand for such models is very high. The main objective was to develop a concept of such a model of extinguishing process, which would allow using a computer to estimate the heat flux received from the combustion zone by the solid jet produced by the selected nozzle. The novelty of proposed model is, among others, determination of sprinkling surface diameter, average surface and number of evaporated droplets based on functions of sprinkling surface and intensity obtained by approximation of experimental data. It allows both to test the effect of selected parameters of the nozzle, such as the angle of inclination and water output on the fire-extinguishing efficiency and determination of the present value of the total received flux that can be used in the fire model.

\section{A physical model of extinguishing process using the solid jet produced by water nozzle}

To build a physical model of extinguishing process using solid jet the following assumptions were adopted:

1. The effect of different diameters of droplets in the stream is neglected.

2. The nozzle output can be constant or variable depending on the type of nozzle, where the nozzle Turbojet 52 performance can be adjusted in the range of 0 to $400 \mathrm{dm}^{3} / \mathrm{min}$ (Placek 2011; PN EN 671-1:2012).

3. Either a solid stream or single droplet trajectory is consistent with equation of ballistic curve in accordance with (Orzechowski, Prywer 2008).

4. Disintegration of a solid stream into droplets is considered, which has been shown in Gałaj and Drzymała (2015), Gałaj and Saramański (2014), Gałaj and Koszykowski (2014), Orzechowski and Prywer (2008). Total drops area $F_{k}[i]$ receiving heat by convection in a time $\tau=1 \mathrm{~s}$ can evaluate with help of the Eqn (1). Functions $F_{z}(\beta)$ and $I_{z}(\beta)$ ap- 
Table 1. A set of sprinkling area function $F_{z}=f(\beta)$ for solid jet obtained as a result of approximation procedure

\begin{tabular}{c|c|c|c}
\hline \multirow{2}{*}{$\begin{array}{c}\text { Pressure } \\
{[\mathrm{MPa}]}\end{array}$} & Sprinkling area function $F_{z}=f(\beta)\left[\mathrm{m}^{2}\right]$ & \multicolumn{2}{|c}{ Inclination angle $[\mathrm{deg}]$} \\
\cline { 3 - 4 } & & $\min$ & $\max$ \\
\hline 0.6 & $I=0.0065 \beta^{2}-0.3473 \beta+7.6725$ & 30 & 45 \\
\hline 0.8 & $F_{z}=0.0038 \beta^{2}-0.1286 \beta+3.71$ & 30 & 45 \\
\hline 1.2 & $F_{z}=0.0069 \beta^{2}-0.3733 \beta+9.2775$ & 30 & 45 \\
\hline
\end{tabular}

Table 2. A set of sprinkling intensity functions $I_{z}=f(\beta)$ for solid jet obtained as a result of approximation procedure

\begin{tabular}{c|c|c|c}
\hline \multirow{2}{*}{$\begin{array}{c}\text { Pressure } \\
{[\mathrm{MPa}]}\end{array}$} & Sprinkling intensity function $I_{z}=f(\beta)[\mathrm{mm} / \mathrm{min}]$ & \multicolumn{2}{|c}{ Inclination angle $[\mathrm{deg}]$} \\
\cline { 3 - 4 } & & $\min$ & $\max$ \\
\hline \multirow{3}{*}{0.6} & $I_{z}=1.936 \beta-13.39$ & 30 & 34 \\
& $I_{z}=5.746 \beta-146.74$ & 35 & 39 \\
& $I_{z}=1.65 \beta+17.1$ & 30 & 45 \\
\hline \multirow{3}{*}{0.8} & $I_{z}=1.624 \beta+2.01$ & 35 & 34 \\
& $I_{z}=7.126 \beta-154.93$ & 40 & 45 \\
\hline \multirow{3}{*}{1.2} & $I_{z}=0.396 \beta+82.6$ & 30 & 34 \\
& $I_{z}=2.05 \beta-7.65$ & 35 & 39 \\
& $I_{z}=7.388 \beta-194.48$ & 40 & 45 \\
\hline
\end{tabular}

pearing in this formula should be selected on the basis of the Tables 1 and 2 for a known value of the inclination angle $\beta$ and one of the three alternative supply pressure of $0.6 \mathrm{MPa}, 0.8 \mathrm{MPa}$ and $1.2 \mathrm{MPa}$. They result from the studies discussed in Gałaj and Drzymała (2015), Gałaj and Saramański (2014), Gałaj and Koszykowski (2014):

$F_{k}[i]=\frac{I_{z}[i] \cdot F_{z}[i] \cdot \tau}{60 \cdot D_{v}[i]}$.

5. In the model supplying of more jets is taken into account. No interactions between them are assumed. This means that the effect of extinguishing of each is considered individually and the final result is a sum of the heat flow received by each of them. The same temperature of drops in all jets is adopted.

6. To calculate the number of drops evaporated $n_{k}[i]$ value $F_{k}[i]$ is used. This value for the $i$-th jet can be determined from the following formula:

$n_{k}[i]=\frac{F_{k}[i]}{\pi \cdot 10^{-6} \cdot D_{v}^{2}[i]}$.

7. Due to significant diameter of sprinkling area by solid stream its calculation is included in the mathematical model, which average value can be obtained from the following equation:

$D_{s}[i]=\sqrt{\frac{4 \cdot F_{z}[i]}{\pi}}$.

8. An arbitrary value of extinguishing effectiveness coefficient $K_{g}<1$ is assumed. It takes into account, among others, stream losses by nozzle - the combustion zone, the mutual interaction of droplets in the stream, a variety of droplet diameter, droplet diameter change due to evaporation.
9. Absence of external influences on the jet, e.g. wind, other factors distorting drops trajectory.

10. All drops have the same velocity.

11. A constant average temperature of the flame is assumed.

12. The heat is received by convection as well as by heating and evaporation of droplets falling on the surface in combustion zone.

13. Drops in the stream evaporate completely only in the combustion zone to the extent specified by coefficient $K_{p}$.

14. The same average diameter of evaporated droplets is assumed.

15. An impact of fire on the pyrolysis process is not taken into account.

16. Impact of limited access of oxygen and fuel as well as chemical reaction in the combustion on extinguishing process are not considered.

17. A cylinder of diameter $D_{f}$ and height $H_{f}$ is adopted as the combustion zone.

18. A mutual configuration of the jet and combustion zone is limited to the following three cases:

a) the stream passes over the combustion zone or does not receive it;

b) the stream reaches the combustion zone, but does not fall on its surface;

c) the stream reaches the combustion zone and falls on its surface.

Projections of horizontal and vertical trajectory of the droplets in the solid jet and its characteristic geometric parameters together with the combustion zone are shown schematically in Figure 1.

According to item 17 of assumptions given in Section 1 , the following mutual configurations of the stream and compact combustion zone are distinguished: 
a) a stream of the $i$-th solid jet does not reach, or flows over the combustion zone, which can be written in the form of the following inequalities:

$$
\begin{aligned}
& \left|\gamma[i]-\operatorname{arctg} \frac{D_{s}[i]}{2 D[i]}\right| \geq \gamma_{\text {max }}[i] \cup z_{\text {max }}[i]- \\
& \frac{D_{s}[i]}{2} \geq H_{f} \cup z_{\text {min }}[i]-\frac{D_{s}[i]}{2} \leq 0,
\end{aligned}
$$

then $\dot{Q}_{g}[i]=0$;

b) a stream of the $i$-th solid jet reaches the combustion zone, but doesn't flow down on its surface, which can be written in the form of the following inequalities:

$$
\left|\gamma[i]+\operatorname{arctg} \frac{D_{s}[i]}{2 D[i]}\right| \leq \gamma_{\max }[i] \cap z_{\max }[i]-\frac{D_{s}[i]}{2} \geq 0,
$$

then: $\quad \dot{Q}_{g}[i]=K_{g} \frac{F_{k}[i] \cdot N u[i] \cdot \lambda}{10^{-3} \cdot D_{v}[i]} \cdot\left(T_{f}-T_{k}\right)$;

c) a stream of the $i$-th solid jet reaches the combustion zone and flows down on its surface, which can be written in the form of the following inequalities:

$$
\begin{gathered}
\left|\gamma[i]+\operatorname{arctg} \frac{D_{s}[i]}{2 D[i]}\right| \leq \gamma_{\max } \cap z_{\max }[i]+\frac{D_{s}[i]}{2} \leq 0, \\
\dot{Q}_{g}[i]=K_{g} \frac{F_{k}[i] \cdot N u[i] \cdot \lambda}{10^{-3} \cdot D_{v}[i]} \cdot\left(T_{f}-T_{k}\right)+
\end{gathered}
$$

$$
K_{p} \cdot n_{k}[i] \frac{d m_{k}}{d t}[i] h_{v}
$$

where:

$$
\begin{aligned}
& \operatorname{Pr}=0.7 ; \\
& S c=0.6 ; \\
& C=112 ;
\end{aligned}
$$

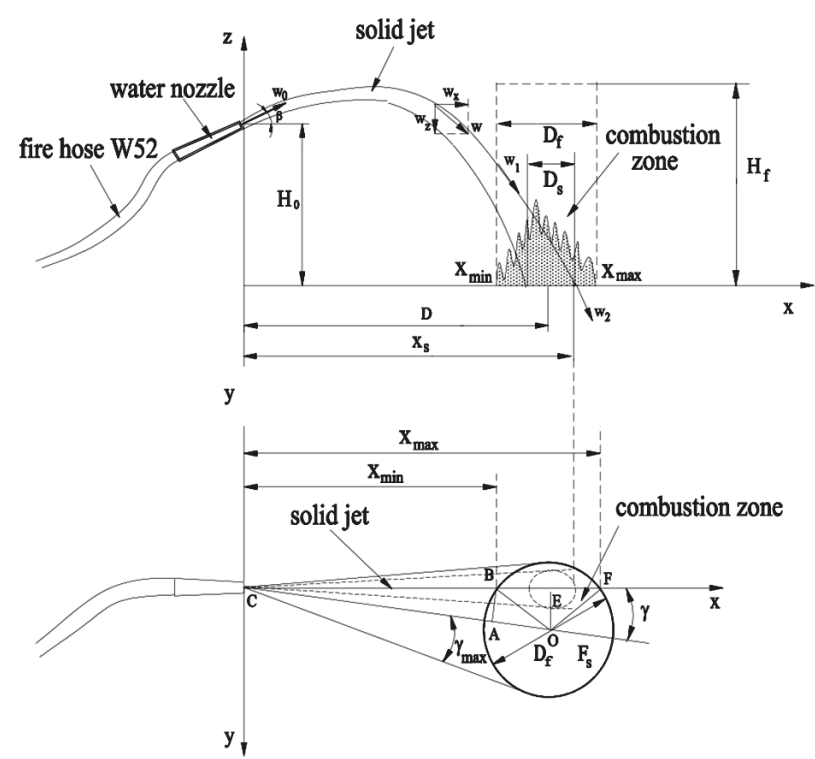

Figure 1. Drops trajectory during the extinguishing process using solid jet (vertical top view, horizontal bottom-view)

$$
\gamma_{\max }[i]=\arcsin \left(\frac{D_{f}}{2 D[i]}\right)
$$

$x_{\min }[i]=D[i] \cdot \cos \gamma[i]-\sqrt{\left(0.5 D_{f}\right)^{2}-D[i]^{2} \cdot \sin ^{2} \gamma[i]}$;

$w_{0}[i]=\frac{16.66 \cdot \dot{V}_{p r}[i]}{\pi \cdot d[i]^{2}}$

$v_{0}=17.08 \cdot 10^{-6} \cdot \frac{T_{0}(273+C)}{273 \cdot \rho_{0} \cdot\left(T_{0}+C\right)} \sqrt{\frac{T_{0}}{273}} ;$

$\lambda_{0}=0.024+\left(T_{0}-273\right) \cdot 6 \cdot 10^{-5} ;$

$K_{1}[i]=\frac{18 \cdot v_{0} \cdot \rho_{0}}{10^{-6} \cdot D_{v}^{2} \cdot \rho_{k}} ;$

$T_{s}=0.5 \cdot\left(T_{f}+T_{k}\right) ;$

$\rho_{g}=\rho_{0} \cdot \frac{T_{0}}{T_{f}}$

$\rho_{s}=0.5 \cdot\left(\rho_{g}+\rho_{k}\right)$;

$v=17.08 \cdot 10^{-6} \cdot \frac{T_{s}(273+C)}{273 \cdot \rho_{s} \cdot\left(T_{s}+C\right)} \sqrt{\frac{T_{s}}{273}} ;$

$\lambda=0.024+\left(T_{s}-273\right) \cdot 6 \cdot 10^{-5}$;

$A_{0}=\frac{\left(\rho_{k}-\rho_{0}\right) \cdot g}{\rho_{k}} ;$

$A_{1}[i]=\operatorname{tg} \beta[i]+\frac{A_{0}}{K_{1}[i] \cdot w_{0}[i] \cdot \cos \beta[i]} ;$

$B_{1}[i]=\frac{A_{0}}{K_{1}[i]^{2}}$;

$z_{\min }[i]=A_{1}[i] \cdot x_{\min }[i]+B_{1}[i]$

$\ln \left(1-\frac{K_{1}[i] \cdot x_{\min }[i]}{w_{0}[i] \cdot \cos \beta[i]}\right)+H_{0}[i]$;

$z_{\max }[i]=A_{1}[i] \cdot x_{\max }[i]+B_{1}[i]$.

$$
\ln \left(1-\frac{K_{1}[i] \cdot x_{\max }[i]}{w_{0}[i] \cdot \cos \beta[i]}\right)+H_{0}[i] ;
$$

$x_{H f}=x_{\min } ;$ for $z_{\min } \leq H_{f}$;

$\left\{\begin{array}{l}A_{1}[i] \cdot x_{H f}[i]+B_{1}[i] \cdot \ln \left(1-\frac{K_{1}[i] \cdot x_{H f}[i]}{w_{0}[i] \cdot \cos \beta[i]}\right)+H_{0}[i]-H_{f} \leq d y \\ x_{H f 0}=x_{\min } \\ x_{H f}=x_{H f}+d x\end{array} ;\right.$

for $z_{\min }>H_{f}$; 


$$
\begin{aligned}
& x_{s}=x_{\max } ; \text { for } z_{\max }>0 \text {; } \\
& \left\{\begin{array}{l}
A_{1}[i] \cdot x_{s}[i]+B_{1}[i] \cdot \ln \left(1-\frac{K_{1}[i] \cdot x_{s}[i]}{w_{0}[i] \cdot \cos \beta[i]}\right)+H_{0}[i] \leq d y \\
x_{s 0}=x_{\max } \\
x_{s}=x_{s}+d x
\end{array} ;\right. \\
& \text { for } z_{\max } \leq 0 \\
& \tau_{1}[i]=-\frac{\ln \left(1-\frac{x_{H f}[i] \cdot K_{1}[i]}{w_{0}[i] \cdot \cos \beta[i]}\right)}{K_{1}[i]} \\
& \tau_{2}[i]=-\frac{\ln \left(1-\frac{x_{s}[i] \cdot K_{1}[i]}{w_{0}[i] \cdot \cos \beta[i]}\right)}{K_{1}[i]} \\
& w_{x 1}[i]=w_{0}[i] \cdot \cos \beta[i] \cdot e^{-K_{1}[i] \cdot \tau_{1}[i]} \\
& w_{z 1}[i]=\left(w_{0}[i] \cdot \sin \beta+A_{0} / K_{1}[i]\right) . \\
& e^{-K_{1}[i] \cdot \tau_{1}[i]}-A_{0} / K_{1}[i] \text {; } \\
& w_{x 2}[i]=w_{0}[i] \cdot \cos \beta[i] \cdot e^{-K_{1}[i] \cdot \tau_{2}[i]} \\
& w_{z 1}[i]=\left(w_{0}[i] \cdot \sin \beta+A_{0} / K_{1}[i]\right) \cdot e^{-K_{1}[i] \cdot \tau_{2}[i]}-A_{0} / K_{1}[i] ; \\
& w_{s}[i]=0.5 \cdot\left(\sqrt{w_{x 1}[i]^{2}+w_{z 1}[i]^{2}}+\sqrt{w_{x 2}[i]^{2}+w_{z 2}[i]^{2}}\right) \\
& \operatorname{Re}[i]=\frac{w_{s}[i] \cdot D_{v}[i] \cdot 10^{-3}}{v} \\
& N u[i]=2+0.6 \cdot \operatorname{Re}[i]^{1 / 2} \cdot \operatorname{Pr}^{1 / 3} \\
& \operatorname{Sh}[i]=2+0.6 \cdot \operatorname{Re}[i]^{1 / 2} \cdot S c^{1 / 3} \\
& \frac{d m_{k}}{d t}[i]=2 \pi \cdot D_{v}[i] \cdot 10^{-3} \cdot \lambda \cdot \ln \left(1+\frac{c_{p} \cdot\left(T_{f}-T_{w}\right)}{h_{v}}\right) . \\
& \left(1+0.3 \cdot \sqrt{\operatorname{Re}[i]} \cdot \operatorname{Pr}^{0.33}\right) / c_{p} ; \\
& \dot{Q}_{g c}=\sum_{i=1}^{\lg } \dot{Q}_{g}[i]
\end{aligned}
$$

\section{The overall concept of simulation studies}

The present simulation is a process in extinguishing a fire with water using a solid jet generated by the nozzle Turbo Master 52. Extinguishing process was limited to direct supply of water to the combustion zone. Simulation tests consisted in introducing different values of constants and variables and performing for them calculations cycle. The following constant input data in the simulation process can be mentioned: a) number of solid jets $l_{g}=1$;

b) the dimensions of the room:

- length of the room $L_{p}=5 \mathrm{~m}$;

- width of the room $W_{p}=5 \mathrm{~m}$;

- room height $H_{p}=3 \mathrm{~m}$;

c) the dimensions of the combustion zone:

- diameter of the combustion zone $D_{f}=5 \mathrm{~m}$;

- height of the combustion zone $H_{f}=2 \mathrm{~m}$;

d) the flame temperature, $T_{f}=800{ }^{\circ} \mathrm{C}$;

e) ratios (for simplicity of analysis, all factors taken equal to unity):

- the evaporation rate determining the percentage of droplets that evaporate completely in relation to the number of all droplets reaching the combustion zone $K_{p}=0.8$;

- extinguishing efficiency ratio $K_{g}=0.8$;

- ratio related to the change in the side surface of the stream as a result of aerodynamic dispersion of droplets and the curvature of the track $K_{f}=1$;

f) step increase in distance when calculating the size of $x s$ and $x h f, d x=0.005 \mathrm{~m}$;

g) the accuracy of the calculation $x$ s and xhf in an iterative loop $d y=0.05 \mathrm{~m}$;

h) the parameters of the position of the nozzle:

- mouth nozzle height above the floor $H_{0}=1 \mathrm{~m}$;

- Ox coordinate of the nozzle mouth position in a coordinate system associated with the room $x_{p}=2 \mathrm{~m}$;

- coordinate $O y$ of the nozzle mouth position in a coordinate system associated with the room $y_{p}=2 \mathrm{~m}$;

i) the diameter of the nozzle mouth $d=12 \mathrm{~mm}$;

j) the deviation angle between the vertical axis of symmetry of the flow and a plane passing through the center of the combustion zone, $\gamma=0 \mathrm{rad}$;

k) stream parameters:

- type of jet - solid;

- average temperature of the water drops $T_{k}=10^{\circ} \mathrm{C}$ $(283 \mathrm{~K})$.

As a variable input data the following can be included: a) the output of the nozzle $\{200 ; 300 ; 400\}\left[\mathrm{dm}^{3} / \mathrm{min}\right]$;

b) inclination angle of the nozzle relative to the level of $\beta\{30,40\}$ [deg].

Average droplet diameter $\overline{D_{v}}$ has been adopted in accordance with the results obtained for solid streams given in Piątek (2016). Distance between firefighter and the combustion zone $D$ was adjusted such that the entire sprinkling surface is inside a burning surface. In this case, the maximum number of drops evaporates. Both of the above values are summarized together with the simulation results in Table 3. Based on the results of experimental work described in Gałaj and Drzymała (2015), Gałaj and Saramański (2014), Gałaj and Koszykowski (2014), which showed approximately constant difference between the calculated and actual values of solid jet ranges, all horizontal distances calculated by the program were reduced by $30 \%$. 
Table 3. Results of simulation tests

\begin{tabular}{c|c|c|c|c|c|c|c|c|c|c|c}
\hline No. & $\begin{array}{c}\beta \\
{[\mathrm{rad}]}\end{array}$ & $\begin{array}{c}\dot{V}_{p r}[i] \\
{\left[\mathrm{dm}^{3} / \mathrm{min}\right]}\end{array}$ & $\begin{array}{c}\overline{D_{v}} \\
{[\mathrm{~mm}]}\end{array}$ & $\begin{array}{c}D \\
{[\mathrm{~m}]}\end{array}$ & $\begin{array}{c}x_{\min } \\
{[\mathrm{m}]}\end{array}$ & $\begin{array}{c}x_{\max } \\
{[\mathrm{m}]}\end{array}$ & $\begin{array}{c}z_{x \min } \\
{[\mathrm{m}]}\end{array}$ & $\begin{array}{c}z_{x \max } \\
{[\mathrm{m}]}\end{array}$ & $\begin{array}{c}x_{s} \\
{[\mathrm{~m}]}\end{array}$ & $\begin{array}{c}x_{H f} \\
{[\mathrm{~m}]}\end{array}$ & $\begin{array}{c}\dot{Q}_{g c} \\
{[\mathrm{~kW}]}\end{array}$ \\
\hline 1 & 30 & 200 & 0.930 & 18.9 & 17.15 & 20.65 & 4.778 & -5.844 & 19.372 & 18.655 & 23.385 \\
2 & 40 & 200 & 1.083 & 22.4 & 20.65 & 24.15 & 6.427 & -7.951 & 22.732 & 22.204 & 22.275 \\
3 & 30 & 300 & 0.978 & 33.6 & 31.85 & 35.35 & 7.346 & -6.211 & 34.265 & 33.775 & 26.363 \\
4 & 40 & 300 & 1.013 & 32.9 & 31.15 & 34.65 & 11.843 & -15.104 & 33.474 & 33.208 & 28.735 \\
5 & 30 & 400 & 1.159 & 63.0 & 61.25 & 64.75 & 6.904 & -6.769 & 63.308 & 62.769 & 22.509 \\
6 & 40 & 400 & 1.125 & 55.3 & 53.55 & 57.05 & 13.513 & -19.701 & 55.573 & 55.338 & 27.172 \\
\hline
\end{tabular}

Figure 2 contains a flowchart of a computer program developed to determine the heat flow received by the current generated by the Turbo Master 52 AWG compact nozzle. It can also be used for different types of nozzles, providing testing of sprinkling area and sprinkling intensity and including corrections of functions shown in Tables 1 and 2 as well as in Figures 3, 4 and 5. Calculations made for the above mentioned combinations of variables would enable input data impact of each of them on the efficiency of firefighting with the use of solid jet measured by the value of the heat flux received from the combustion zone. The results of simulation tests are included in the next section.

\section{Results of simulation process}

The results of simulation studies for the six analyzed extinguishing processes at different inclination angles and nozzle outputs are included in Table 3. Selected relationships are shown graphically in Figures 6 and 7.

Table 3 contains either input or output data of simulation program. The following input data are included in the table: inclination angle $\beta$, nozzle output $V_{p r}[i]$ and average droplets diameter $\overline{D_{v}}$. The following output data (simulation results) are included in the table: horizontal distance between the nozzle outlet and the center of the combustion zone $D$, horizontal distances between proximal and distal edge of combustion zone and nozzle outlet $x_{\min }$ and $x_{\max }$, coordinates $\mathrm{O} z$ of the drop trajectory point, which corresponds to the coordinates $x_{\min }$ and $x_{\max }$ respectivaly $z_{\min }$ and $z_{\max }$. horizontal distance between the point of intersection of the drop trajectory with the ground surface and the nozzle outlet of the $i$-th $x_{s}$, horizontal distance between the point of intersection of the drop trajectory with combustion zone and the nozzle outlet $x_{H f}$ and mean heat flux received from the combustion zone by solid jet $\dot{Q}_{g}$. Based on the values contained in the Table 3 and Figures 6-7 it can be stated that the greatest value of heat flux received by the solid jet is equal to about $28.73 \mathrm{~kW}$, corresponding to the most extinguishing effectiveness, for the inclination angle of $40^{\circ}$ and the nozzle output of $300 \mathrm{dm}^{3} / \mathrm{min}$ was obtained. In turn, the smallest value of received heat flux of about $22.27 \mathrm{~kW}$ for the same angle but with the output of $200 \mathrm{dm}^{3} / \mathrm{min}$ was received.

\section{Conclusions}

The physical and mathematical model of the extinguishing process was constructed using a solid jet produced by a water nozzle. On this basis a computer program was developed which was used to simulate the extinguishing process. Simulation tests for various inclination angles and nozzle output were conducted. The basic output value for fire extinguishing efficiency was the heat flux received from the combustion zone. Considering the presented concept and results obtained during simulation tests the following general conclusions can be formulated:

1. Taking into account all the scenarios examined for assumed input data the average value of the heat flux received by the solid jet is approximately $25 \mathrm{~kW}$.

2. Either nozzle output or its angle of inclination slightly affects the flow of heat received from the combustion zone by the solid jet supplied by it. The difference between the maximum and minimum values of the heat flux is about $6.5 \mathrm{~kW}$ and which is about $26 \%$ of its average value.

3. For larger nozzle output ( 300 and $400 \mathrm{dm}^{3} / \mathrm{min}$ ) increasing the inclination angle increases of the heat flux, but at lower flow rates, this trend is reversed.

4. The highest mean value of the heat flux received by solid jet at nozzle output of $300 \mathrm{dm}^{3} / \mathrm{min}$ is obtained.

5. Due to the relatively simple mathematical procedures with no complex integration or differentiation to derive the result is almost immediate.

6. After appropriate modifications of the functions of sprinkling area and intensity the proposed model can be used for any type of nozzle.

7. Basic relationships related both to the trajectory of the drops and heat exchange can be used for extinguishing model using spray jets.

8. In order to approximate the proposed model to real conditions, a distribution of average diameters of drops falling on the sprinkling area of irrigation and its dimensions should be included. Assuming that we are dealing still with air, it will depend on several factors such as output and pressure at the nozzle and its angle of inclination. A study related to drops distribution and dimensions of the sprinkling area are planned for this year. 


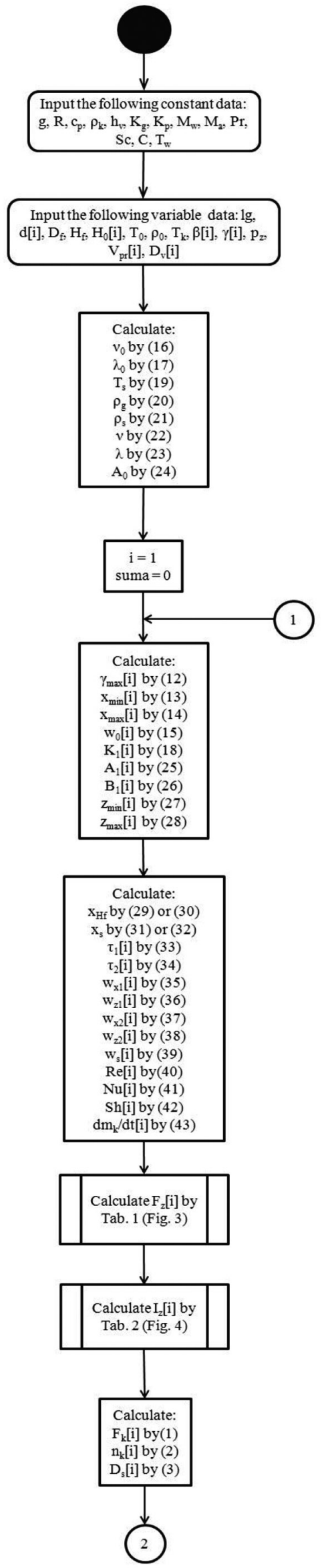

Figure 2. Flowchart of a main computer program (part 1)

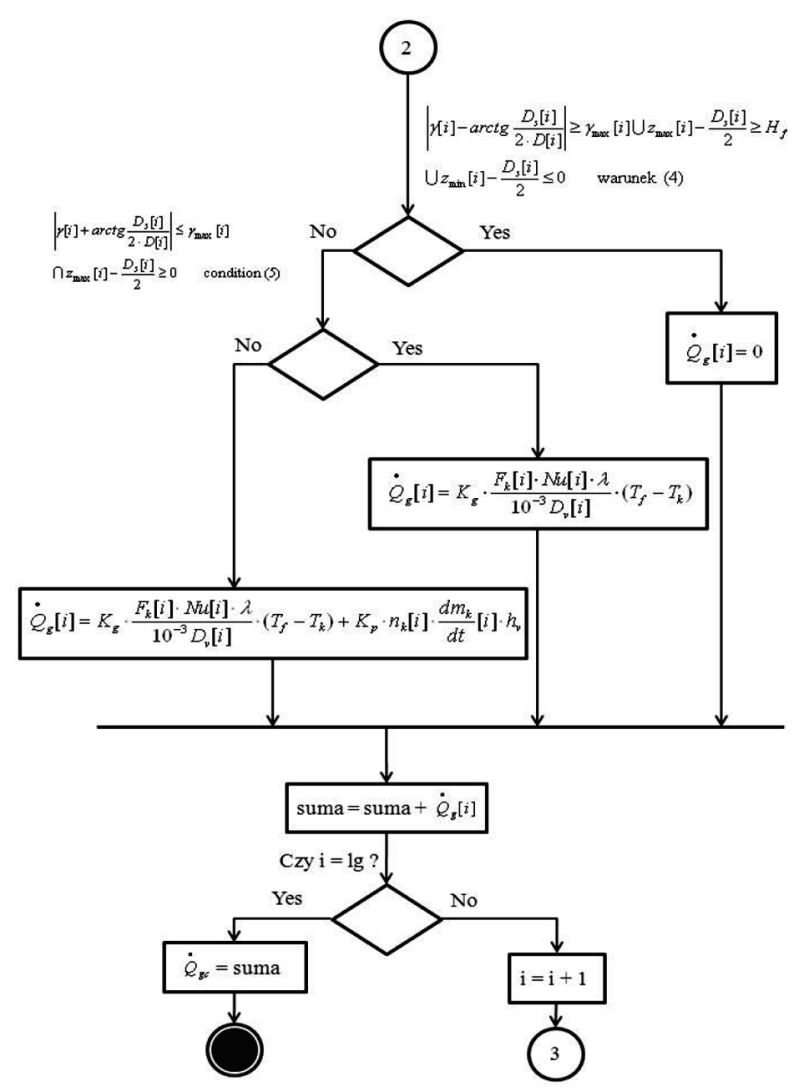

Figure 3. Flowchart of a main computer program (part 2)

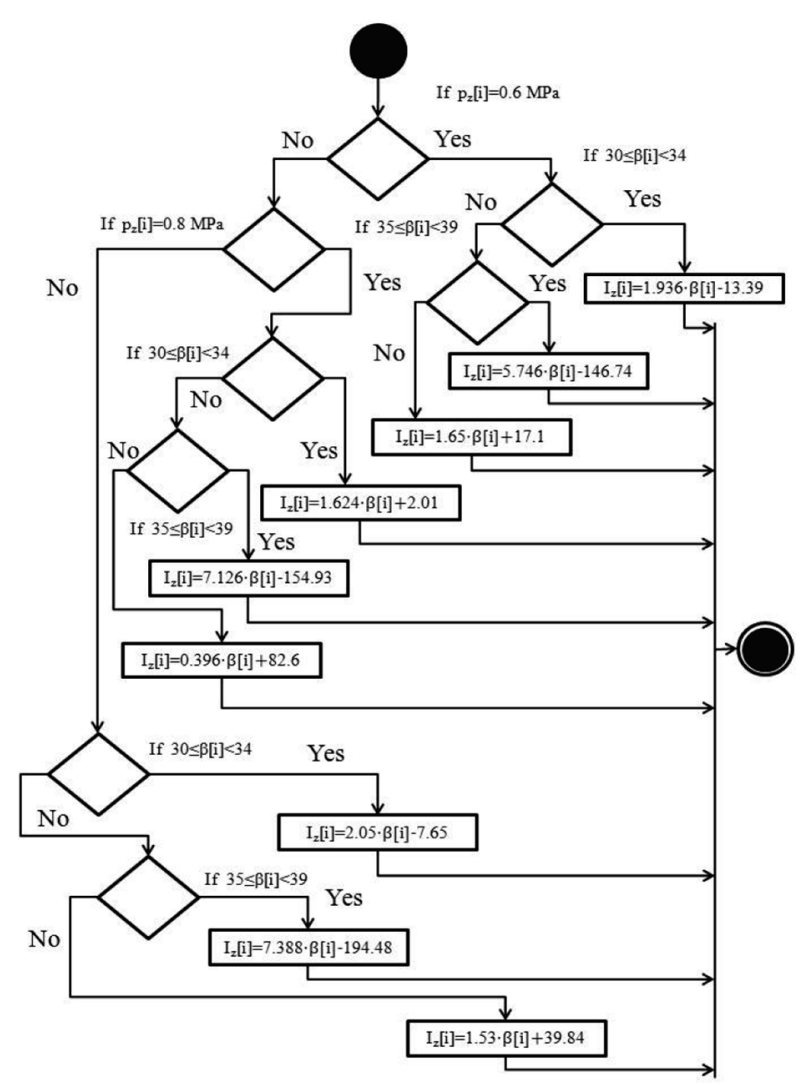

Figure 4. Flowchart of a procedure designed for calculation of sprinkling area functions $F_{z}$ 


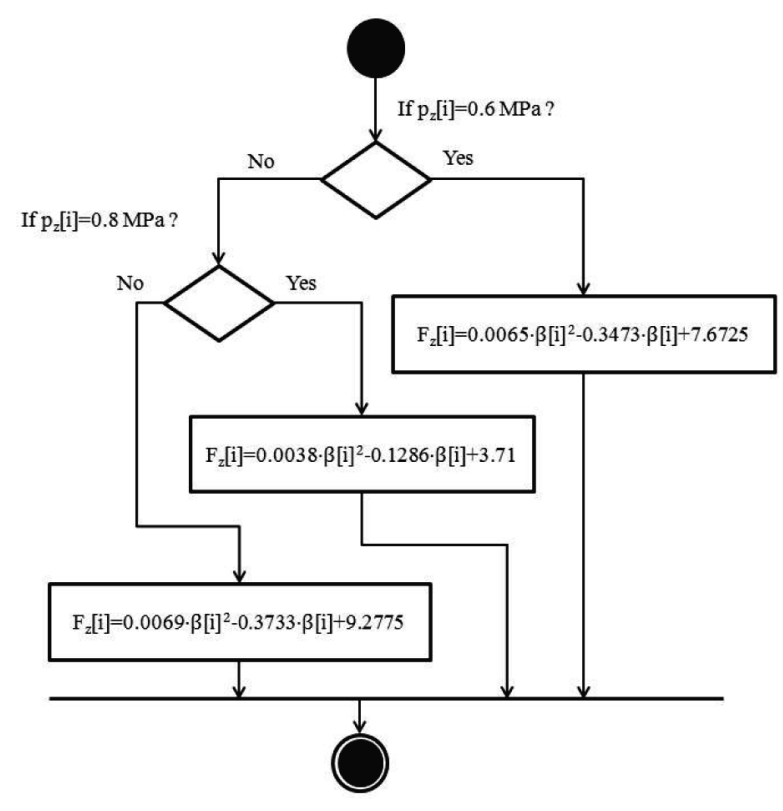

Figure 5. Flowchart of a procedure designed for calculation of sprinkling intensity functions $I_{z}$

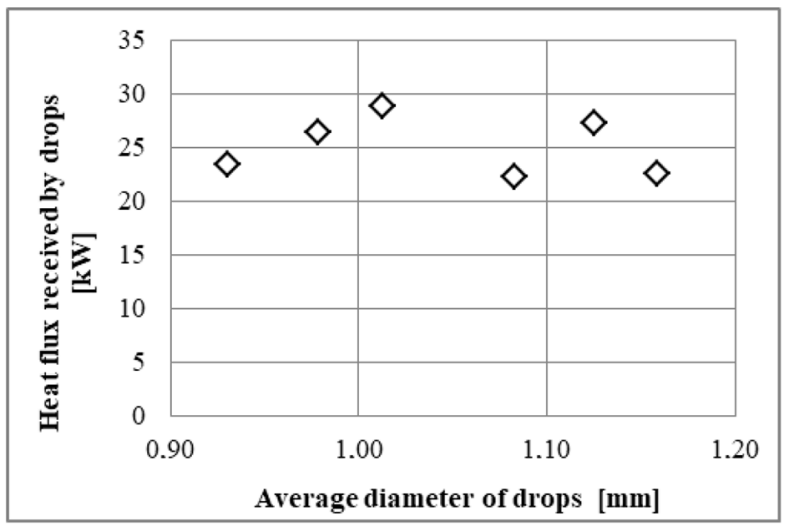

Figure 6. Heat received by drops vs average diameter of drops

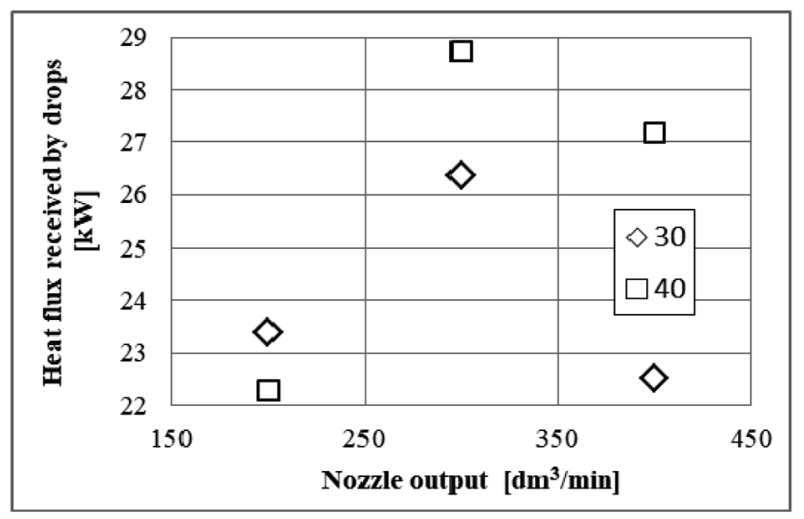

Figure 7. Heat received by drops vs nozzle output for two different inclination angles
9. To take full advantage of its features, the model of fire extinguishing with water nozzles should be associated with any field fire model, e.g. the hybrid model described in Gałaj (2009) and Gałaj et al. (2016).

10. In order to check a convergence of the proposed model to the real process, it is necessary to carry out its validation. This could be done by measuring the heat flux emitted during the comparable fire (the same combustible material in the same amount and the same location in the room) without suppression and with suppression (the parameters associated with the suppression process should be identical to those introduced into the model). The experiments are planned for the near future.

\section{Notation}

C - constant approximately equal to 112 ;

$c_{p} \quad$ - isobaric specific heat of water droplet in the combustion zone assumed to be constant value of $4190 \mathrm{~J} / \mathrm{kgK}$;

$d[i]$ - diameter of the $i$-th nozzle mouth [mm];

$D[i] \quad$ - horizontal distance of the mouth of the $i$-th water nozzle from the center of the combustion zone [m];

$D_{f} \quad$ - diameter of combustion zone $[\mathrm{m}]$;

$d y$ - assumed accuracy of the estimates of the $y$-coordinate of intersection point of the droplets trajectory with combustion zone $[\mathrm{m}]$;

$d m_{k}[i] / d t$ - average mass velocity of the single droplet vaporizing from the surface corresponding to the $i$-th solid jet $[\mathrm{kg} / \mathrm{s}]$;

$D_{v}[i]$ - average volume droplet diameter of $i$-th extinguishing jet $[\mathrm{mm}]$;

$D_{w}$ - diffusion coefficient of water into the air assumed to be approximately constant and equal to $225 \times 10^{-3}\left[\mathrm{~m}^{2} / \mathrm{s}\right]$;

$d x \quad$ - elementary step of $x$-coordinate [m];

$F_{\mathrm{z}}[i]$ - sprinkling surface of $i$-th solid jet $\left[\mathrm{m}^{2}\right]$;

$g \quad$ - acceleration due to gravity assumed to be constant equal to $9.81 \mathrm{~m} / \mathrm{s}^{2}$;

$H_{0}[i]$ - height of the mouth of the $i$-th water nozzle above the floor $[\mathrm{m}]$;

$H_{f} \quad$ - height of combustion zone [m];

$h_{v} \quad$ - evaporation heat assumed to be constant of $2020 \mathrm{~J} /$ $\mathrm{kg}$;

$I_{z}[i]$ - sprinkling intensity of $i$-th solid jet $[\mathrm{mm} / \mathrm{min}]$;

$K_{g} \quad$ - extinguishing effectiveness coefficient [-];

$K_{p} \quad$ - evaporation coefficient determining the percentage of droplets that evaporate completely in relation to the number of all droplets reaching the combustion zone [-];

lg - number of extinguishing lines;

$M_{w} \quad$ - molar weight of water molecule assumed to be constant value of $18 \mathrm{~kg} / \mathrm{mol}$;

$n_{k}[i]$ - number of droplets completely vaporizing in the combustion zone; 
$\mathrm{Nu}[i]$ - Nusselt number corresponding to droplets of the $i$-th solid jet [-];

$\mathrm{Pr} \quad$ - Prandtl number assumed to be approximately constant value of 0.7 ;

$Q_{g}[i]$ - mean heat flux received from the combustion zone by the $i$-th extinguishing jet [W];

$r \quad$ - universal gas constant $[\mathrm{J} /(\mathrm{mol} \cdot \mathrm{K})]$;

$\operatorname{Re}[i]$ - Reynolds number corresponding to droplets of the $i$-th solid jet [-];

Sc - Schmidt number assumed to be approximately constant value of $0.6[-]$;

$S h[i]$ - Sherwood number corresponding to droplets of the $i$-th solid jet [-];

$T_{f} \quad$ - average temperature of the flame in the combustion zone $[\mathrm{K}]$;

$T_{k} \quad$ - average temperature of water droplet [K];

$T_{w} \quad$ - boiling temperature of the water assumed to be constant and equal to $373 \mathrm{~K}$;

$V_{\text {pr }}[i]$ - output of $i$-th water nozzle $\left[\mathrm{dm}^{3} / \mathrm{min}\right]$;

$w_{0}[i]-$ average drops velocity produced by the $i$-th water nozzle $[\mathrm{m} / \mathrm{s}]$;

$w_{s}[i]$ - average velocity of drops flowing through combustion zone for the $i$-th extinguishing jet $[\mathrm{m} / \mathrm{s}]$;

$w_{x 1}[i]$ - horizontal component of drops velocity in the $i$-th jet at the entrance into the combustion zone $[\mathrm{m} / \mathrm{s}]$;

$w_{x 2}[i]$ - horizontal component of drops velocity in the $i$-th jet at the exit of combustion zone $[\mathrm{m} / \mathrm{s}]$;

$w_{z 1}[i]$ - vertical component of drops velocity in the $i$-th jet at the entrance into the combustion zone $[\mathrm{m} / \mathrm{s}]$;

$w_{z 2}[i]$ - vertical component of drops velocity in the $i$-th jet at the exit of combustion zone $[\mathrm{m} / \mathrm{s}]$;

$x_{H f}[i]$ - horizontal distance between the point of intersection of the drop trajectory with combustion zone and the outlet of the $i$-th nozzle $[\mathrm{m}]$;

$x_{\max }[i]$ - horizontal distance between distal edge of combustion zone and mouth of the $i$-th water nozzle $[\mathrm{m}]$;

$x_{\min }[i]$ - horizontal distance between proximal edge of combustion zone and mouth of the $i$-th water nozzle $[\mathrm{m}]$;

$x_{s}[i]^{\prime}$ - horizontal distance between the point of intersection of the drop trajectory with the ground surface and the outlet of the $i$-th nozzle [m];

$z_{\max }[i]-i$-th coordinate $O z$ of the drop trajectory point, which corresponds to the coordinate $x_{\max }[i][\mathrm{m}]$;

$z_{\min }[i]-i$-th coordinate $\mathrm{O} z$ of the drop trajectory point, which corresponds to the coordinate $x_{\min }[i][\mathrm{m}]$;

$\beta[i] \quad$ - inclination angle of the $i$-th water nozzle [rad];

$\gamma[i] \quad$ - angle between the vertical axis of jet symmetry of the $i$-th jet and a plane passing through the center of combustion zone [rad];

$\gamma_{\max }[i]$ - angle between the $i$-th vertical plane passing through the center of the combustion zone and a plane containing a tangent to a circle forming the combustion zone [rad]; $\lambda$ - average conductivity coefficient of the gaseous medium in the combustion zone $[\mathrm{W} / \mathrm{mK}]$;

$\lambda_{0}$ - conductivity coefficient of the ambient air outside the combustion zone assumed to be approximately constant equal to $0.024 \mathrm{~W} / \mathrm{mK}$;

$v$ - kinematic viscosity of the air inside the combustion zone $\left[\mathrm{m}^{2} / \mathrm{s}\right]$;

$v_{0} \quad$ - kinematic viscosity of ambient air outside the combustion zone $\left[\mathrm{m}^{2} / \mathrm{s}\right]$;

$\rho_{0} \quad$ - average density of the air outside combustion zone assumed to be constant value of $1.23 \mathrm{~kg} / \mathrm{m}^{3}$;

$\rho_{k}$ - density of water droplet assumed to be constant value of $1000 \mathrm{~kg} / \mathrm{m}^{3}$;

$\tau$ - computing time, usually equal to $1 \mathrm{sec}$;

$\tau_{1} \quad$ - time to reach the combustion zone by the $i$-th solid jet $[s]$;

$\tau_{2} \quad$ - time to reach the sprinkling surface by the $i$-th solid jet $[\mathrm{s}]$.

\section{References}

Babinsky, E.; Sojka, P. E. 2002. Modeling drop size distributions, Progress in Energy and Combustion Science 28: 303-329. https://doi.org/10.1016/S0360-1285(02)00004-7

Gałaj, J. 2009. A general concept of fire hybrid modelling in compartments, Journal of Civil Engineering and Management 15(3): 237-245.

https://doi.org/10.3846/1392-3730.2009.15.237-245

Gałaj, J.; Drzymała, T. 2015. Analysis of the impact of water flow on sprinkling intensity by the spray produced by the nozzle Turbo Master 52, Logistics 5: 929-950 (in Polish).

Gałaj, J.; Konecki, M.; Sukys, R. 2016. Simulation tests of extinguishing process using mist nozzles with application of hybrid fire model, Journal of Civil Engineering and Management 22(4): 573-583.

https://doi.org/10.3846/13923730.2016.1159248

Gałaj, J.; Koszykowski, R. 2014. Study on the impact of angular position and output of chosen water monitor on decomposition of solid jet into the spray, Logistics 6: 3736-3747 (in Polish).

Gałaj, J.; Saramański, S. 2014. Studies on the impact of angular position and supply pressure on sprinkling area and intensity using solid jet produced by the nozzle PWT 52 TURBOSUPON, Logistics 5: 471-480 (in Polish).

Grant, G.; Brenton, J.; Drysdale, D. 2000. Fire suppression by water sprays, Progress in Energy and Combustion Science 26(2): 79-130. https://doi.org/10.1016/S0360-1285(99)00012-X

Grimwood, P. 2002. Flashover \& nozzle techniques. Tactical firefighting. London: CEMAC.

Marshall, A. W.; di Marzo, M. 2004. Modeling aspects of sprinkler spray dynamics in fires, Process Safety and Environmental Protection 82(B2): 97-104.

https://doi.org/10.1205/095758204322972744

Myers, T.; Marshall, A. W. 2016. A description of the initial fire sprinkler spray, Fire Safety Journal 84: 1-7. https://doi.org/10.1016/j.firesaf.2016.05.004

Novozhilov, V. 2007. Optimum water sprays for firefighting. AOSFT 7.

Orzechowski, Z.; Prywer, J. 2008. Production and application of fluid spray. Warsaw: WNT (in Polish). 
Piactek, P. 2016. Analysis of the impact of inclination angle on distribution of droplets diameters in a spray produced by the nozzle Turbo master 52: Master thesis. Warsaw: SGSP (in Polish).

Placek, P. 2011. Water equipment and fitting. Warsaw (in Polish).

PN EN 671-1:2012 Fixed extinguishing system, internal hydrants, internal hydrants with semi-rigid hose. Polish standard.

Ren, N.; Baum, H. R.; Marshall, A. W. 2011. A comprehensive methodology for characterizing sprinkler sprays, Proceedings of the Combustion Institute 33(2): 2547-2554. https://doi.org/10.1016/j.proci.2010.06.107

Salyers, B. E. 2010. Spray characteristics from fire hose nozzles: Master thesis. University of Maryland.

Särdqvist, S. 2016. Water and other extinguishing agents. Swedish Rescue Services Agency, Sweden. 336 p.

Svensson, S.; Särdqvist, S. 2002. Paper II: Fire tests in a large hall, using manually applied high - and low - pressure water sprays, in S. Svensson (Ed.). The operational problem of fire control. Lund: Department of Fire Safety Engineering and Systems Safety, Lund University.

White, J. P.; Vilfayeau, S.; Marshall A. W.; McDermott, R. J. 2017. Modeling flame extinction and reignition in large eddy simulations with fast chemistry, Fire Safety Journal 90: 72-85. https://doi.org/10.1016/j.firesaf.2017.04.023

Willi, J. M.; Madrzykowski, D.; Weinschenk, C. 2016. Impact of hose streams on air flows inside a structure. NIST Technical Note 1938.

Wu, D.; Guillemin, D.; Marshall, A. W. 2007. A modeling basis for predicting the initial sprinkler spray, Fire Safety Journal 42: 283-294. https://doi.org/10.1016/j.firesaf.2006.11.007

Yoon, S. S. 2005. Droplet distribution at the liquid core of a turbulent spray, Physics of Fluids 17: 035103. https://doi.org/10.1063/1.1852577

Zbrożek, P.; Prasuła, J. 2009. The influence of water mist drop diameter on the efficiency of fires suppression and cooling, Safety and Fire Technique 3: 113-148 (in Polish).

Zheng, Y.; Ryder, N.; Marshall, A. W. 2010. Model development for predicting fire hose stream characteristics [online], [cited 22 Oct 2017]. Available from Internet:

http://www.nfpa.org/ /media/files/news-and-research/resources/research-foundation/foundation-proceedings/2012supdet/29zheng-et-al-extended-abstract.pdf?la=en 